\title{
Adolescent girls' access to contraceptive information and services: An analysis of legislation and policies, and their realisation, in Nigeria and South Africa
}

\author{
Oluremi A Savage-Oyekunle* \\ Doctoral candidate, Faculty of Law, University of Pretoria, South Africa; \\ Lecturer, Lagos State University, Lagos, Nigeria
}

\section{Annelize Nienaber**}

Associate Professor of Law, Faculty of Law, University of Pretoria, South Africa

\section{Summary}

Adolescents' early sexual debut contributes to their huge burden of sexual and reproductive ill-health, especially in sub-Saharan Africa. Reports continually reveal that female adolescents, in particular, constitute a large portion of the 34 million people living with HIV worldwide. Other consequences associated with early adolescent sexuality include unplanned pregnancies, unsafe abortions and sexually-transmitted infections. In light of this, the article analyses approaches adopted by Nigeria and South Africa in fulfilling their international law obligations to respect, protect and fulfil adolescent girls' right to access contraceptive information and services, specifically, in their domestic legislation, policy documents and court decisions. Sexuality education is compared, as well as actual access. There is extensive evidence of the measures put in place to ensure adolescent girls' access to contraceptive information and services in Nigeria and South Africa. Although the level and extent of the barriers faced by adolescent girls when accessing contraceptive services

\footnotetext{
LLB LLM (Lagos State), LLD (Pretoria); remisavage@yahoo.com. The article is based on sections of the first author's doctoral thesis.

** LLM LLD (Pretoria); annelize.nienaber@up.ac.za
} 
and information vary, the consequences are similar: We find that Nigerian and South African adolescent girls, generally, lack access to contraceptive information and services. Despite measures to ensure adolescent girls' access to contraceptive information and services in Nigeria and South Africa, several gaps remain.

Key words: Adolescent girls; access to health care; contraceptive information and services; Nigeria; South Africa; sexuality education

\section{Introduction}

At present, 88 per cent of the world's adolescent population resides in developing countries, ${ }^{1}$ many of them in sub-Saharan Africa where one in every five inhabitants is an adolescent. ${ }^{2}$ Such a large adolescent population presents an opportunity for economic development and is a foundation for remodelling the future of countries in the African region. ${ }^{3}$

Adolescence presents an opportunity to establish a foundation for a healthy and productive adulthood, but it is also a period of risk for sexual and reproductive health (SRH) problems with immediate or future consequences. ${ }^{4}$ Statistics indicates that adolescents start engaging in intimate sexual relations at a progressively younger age, and this behaviour has been linked to an increase in adolescent pregnancies and sexually-transmitted infections (STIs). ${ }^{6}$ Consequently, it is of vital importance that adolescents gain access to comprehensive reproductive health care, including contraceptive services and information, in order to reduce the threats occasioned by the expression of their sexuality.

Regrettably, access to comprehensive contraceptive services and information continues to elude adolescents in sub-Saharan Africa, and

1 UNICEF Demographic trends for adolescents: Ten key facts http://www.unicef.org/ sowc2011/pdfs/Demographic-Trends.pdf (accessed 31 March 2014).

2 As above; RJ Cook et al Reproductive health and human rights, integrating medicine, ethics and law (2003) 276.

3 Population Reference Bureau 'The time is now: Invest in sexual and reproductive health for young people' (2012) http://www.prb.org/pdf12/engage-youth-keymessages.pdf (accessed 31 March 2013); EY Jimenez et al World Development Report 2007: Development and the next generation (2006) 26-28.

$4 \quad$ WHO Strengthening the health sector response to adolescent health and development (2010) 2.

5 AS Madkour et al 'Early adolescent sexual initiation and physical/psychological symptoms: A comparative analysis of five nations' (2010) 39 Journal of Youth and Adolescence 1213; BO Nwankwo \& EA Nwoke EA 'Risky sexual behaviours among adolescents in Owerri municipal: Predictors of unmet family health needs' (2009) 13 African Journal of Reproductive Health 136.

6 Nwankwo \& Nwoke (n 5 above) 136; RS French \& FM Cowan 'Contraception, best practice and research' (2009) 23 Clinical Obstetrics and Gynecology 234. 
it is adolescent girls, in particular, who bear the burden of sexual and reproductive ill health. ${ }^{7}$ A considerable number of new HIV infections occur in young African women. ${ }^{8}$ In addition, while the occurrence of unintended pregnancies among adolescents is a common public health problem worldwide, ${ }^{9}$ the situation is particularly grave in subSaharan Africa, where teenage fertility rates in 2013 amounted to a staggering 101 per 1000 adolescents. Early pregnancy is a major cause of morbidity and mortality among adolescent girls between the ages of 15 and 19 in Africa. ${ }^{10}$ Also, female adolescents account for over 14 per cent of unsafe abortions that occur yearly as a result of unwanted pregnancies. ${ }^{11}$

Because of this dire situation, numerous human rights instruments, including the International Covenant on Economic, Social and Cultural Rights (ICESCR), the Convention on the Rights of the Child (CRC), the African Charter on Human and Peoples' Rights (African Charter), the African Charter on the Rights and Welfare of the Child (African Children's Charter) and the Protocol to the African Charter on Human and Peoples' Rights on the Rights of Women in Africa (African Women's Protocol), ${ }^{12}$ which guarantee adolescents' right to health care, ${ }^{13}$ and other consensus documents, led by the ICPD Programme of Action, ${ }^{14}$ have been promulgated. They all support the idea that a successful transition into adulthood requires the realisation of access to adolescent-friendly health services and access to health-promoting information on sexual and reproductive matters. ${ }^{15}$

7 E Durojaye 'Access to contraception for adolescents in Africa: A human rights challenge' (2011) 44 Comparative and International Law Journal of Southern Africa 2.

8 UNAIDS Special report: How Africa turned AIDS around (2013) 6-7; UNAIDS World AIDS Day report (2011) 10.

9 S Ramos 'Interventions for preventing unintended pregnancies among adolescents' (2011) WHO Reproductive Health Library Commentary (2011) http:// apps.who.int/rhl/adolescent/cd005215_ramoss_com/en/index.html (accessed 31 March 2014).

10 As above; Population Reference Bureau The world youth: 2013 data sheet (2013) 11.

11 RJ Cook et al 'Respecting adolescents' confidentiality and reproductive and sexual choices' (2007) 98 International Journal of Gynecology and Obstetrics 183.

12 In this article we do not present an overview of the guarantees of adolescents' right to health care in each international and regional human rights instrument. For such an overview, see Durojaye (n 7 above); OA Savage-Oyekunle \& A Nienaber 'Adolescent girls' access to contraceptive information and services in South Africa: What is going wrong?' (2015) Journal of Contemporary Roman-Dutch Law (in press); and OA Savage-Oyekunle 'Female adolescents' reproductive health rights: Access to contraceptive information and services in Nigeria and South Africa' unpublished LLD thesis, University of Pretoria, 2014 ch 2.

13 Cook et al (n 11 above).

14 International Conference on Population and Development Programme of Action 1994 http://www.unfpa.org/public/publications/pid/1973 (accessed 31 March 2014).

15 SJ Jejeebhoy et al 'Meeting the commitments of the ICPD Programme of Action to young people' (2013) 21 Reproductive Health Matters 18. 
In a large number of countries, also on the African continent, human rights guarantees regarding adolescents' right to health care have been incorporated in domestic legislation. With this in mind, the article reports on a study which compares the approaches adopted by Nigeria and South Africa in fulfilling their international law obligations to respect, protect and fulfil adolescent girls' rights of access to contraceptive and reproductive health care and, specifically, the steps taken by each country in their domestic legislation to realise adolescent girls' access to contraceptive information and services.

Nigeria and South Africa were chosen for a comparative analysis for a number of reasons, in addition to the two authors' familiarity with the two countries' legal systems. Reasons for focusing on Nigeria and South Africa include the following:

(a) Nigeria and South Africa both display societal factors reflecting the subordination of women due to cultural factors which place men as 'natural' superiors over women.

(b) The two countries are signatories to various international human rights instruments and declarations which provide for the recognition and protection of women's reproductive health care rights.

(c) Although the two countries exhibit different legal traditions and histories, both are governed by an array of domestic legislation aimed at addressing their populations' health rights. Legislation granting the right to reproductive health care to women and adolescent girls is clearly defined in South Africa. In the case of Nigeria, it is not. Reasons for differences between the two countries in this regard may be enlightening.

(d) Both countries are regarded as sub-regional economic powers on the African continent. The ability of adolescents to effectively access health care information and services has important implications for the two countries' economic development.

Below we examine the national legislation of Nigeria and South Africa regarding adolescent girls' rights to independently access and consent to confidential contraceptive information and services, after which we survey the two countries' approaches to teaching sexuality education and the realisation of adolescent girls' access to sexual and reproductive health care services. In other words, the focus here does not extend to a discussion of the international normative framework. In so far as it is integrated into the domestic legal regime, international law, however, remains relevant. Next, we compare the role played by the courts in both countries in ensuring government compliance with the duty to respect, protect and fulfil the right to health care of adolescent girls so as to draw conclusions in the final section of the article. 


\section{National legislation of Nigeria and South Africa ensuring adolescent girls' access to contraceptive information and services}

Several similarities, but also differences, exist in the legal frameworks adopted by Nigeria and South Africa in protecting the human rights of their citizens, as well as with regard to the rights of adolescent girls to contraceptive information and services. Although both Nigeria and South Africa are signatories and parties ${ }^{16}$ to human rights treaties and declarations affirming the protection of the right to health and sexual and reproductive health, they differ in their methods of interpretation, protection, enforcement and in the limitations placed upon the enjoyment of these rights. The central focus in this section, therefore, is on highlighting these similarities and differences in relation to the findings of the article.

Both countries have legislation and policies in place to protect children's rights and both countries have domesticated international and regional human rights instruments guaranteeing the rights of children. In addition to the Child Rights Act (in Nigeria) and the Children's Act (in South Africa), which domesticate provisions of the CRC and African Children's Charter, Nigeria and South Africa have other statutes and policies that guarantee and protect female adolescents' SRH rights, including their right to access contraceptive services and information. ${ }^{17}$

However, despite the above similarity, it is important to point out that the level of commitment invested in ensuring female adolescents' protection and access to contraceptive information and services differs in the two countries. An example to support this assertion relates to the fact that, whereas South Africa recently adopted the National Contraception and Fertility Planning Policy and Service Delivery Guidelines to establish a system that is constantly monitoring the implementation of its policies in order to correct shortcomings, 18 in the case of Nigeria the opposite is the case, as the current National

16 It is necessary to highlight the fact that South Africa only ratified the ICESCR in January 2015. For an in-depth comparative study of the relevant treaties and their incorporation in the two countries, see OA Savage-Oyekunle \& A Nienaber 'Female adolescents' evolving capacities in relation to their right to access contraceptive information and services: A comparative study of South Africa and Nigeria' (2015) 48 Comparative and International Law Journal of Southern Africa 98.

17 While Nigeria has in place the National Health Policy 2004 the National Reproductive Health Policy 2001, National Policy on Health and Development of Adolescents and Young People 2007, and the National Youth Policy 2009, among others, South Africa has the National Health Act, the Choice on Termination of Pregnancy Act, the Integrated School Health Policy and the National Contraception and Fertility Planning and Service Delivery Guideline 2012, among others.

18 Para 6.1.2 National Contraception and Fertility Planning Policy and Service Delivery Guidelines http://www.doh.gov.za/docs/policy/2013/contraception_ fertility_planning.pdf (accessed 3 May 2013). 
Reproductive Health Policy, which replaced the Maternal and Child Health Policy, was adopted as long ago as 2001 with no further amendment made to it to date. ${ }^{19}$ In Nigeria there is no recent policy on SRH, especially for adolescents in the country: The present National Policy on Health and Development of Adolescents and Young People was adopted in 2007.

In Nigeria there are no genuine efforts to co-ordinate the implementation of existing policies or effectively monitor their performance. The above assertion is based on the reasoning that the existence of frequent monitoring mechanisms would reveal defects in need of review in the existing policies, resulting in action for their correction. ${ }^{20}$

South Africa's recently-adopted Integrated School Health Policy, which enables adolescents to access SRH care services and information in the school context, is a positive step. This is a major area of difference in the approaches adopted by Nigeria and South Africa in fulfilling the rights of female adolescents to access contraceptive information and services: Nigeria presently does not have a programme of this kind. In addition, South Africa has succeeded in passing a National Health Act which has been in operation since 2005, whereas Nigeria's proposed National Health Bill has been a source of serious contention among various health groups since 2008 when moves towards its adoption were initiated. ${ }^{21}$

Finally, unlike the African Youth Charter and South Africa's National Youth Policy, ${ }^{22}$ which extend the scope of protection offered in terms of age to between the ages of 14 and 35 years and which contain various youth-oriented provisions, including those relating to the management of SRH issues, the Nigerian Youth Policy actually narrowed the scope of adolescents and youths protected to those between the ages of 18 and 35 years. ${ }^{23}$ This move not only contravenes age stipulations contained in the African Youth Charter, but also adopts an unrealistic attitude towards adolescent sexuality. Nigeria needs to correct its attitude in relation to the issues raised.

19 The Maternal and Child Health Policy was replaced by the National Reproductive Health Policy due to a paradigm shift which sought to protect reproductive health, generally, rather than only maternal, child health and family planning.

$20 \mathrm{NI}$ Aniekwu The development of reproductive health laws: Considerations for the Nigerian legal system (2006) 1; NI Aniekwu Engendering sexuality: Human rights issues in reproductive and sexual health (2006) 38.

21 S Ayo-Aderele Rid proposed Health Bill of contentious items - CSOs (2013) http:// www.punchng.com/health/rid-proposed-health-bill-of-contentious-items-csos/ (accessed 21 March 2013).

22 National Youth Policy 2009-2014 http://www.thepresidency.gov.za/MediaLib/ Downloads/Home/Publications/YouthPublications/NationalYouthPolicyPDF/NYP. pdf (accessed 6 April 2013).

23 Para 1.3 Nigerian Youth Policy (n 22 above). 


\section{Comparing approaches to sexuality education in Nigeria and South Africa}

Both Nigeria and South Africa currently have sexuality education programmes which address SRH information to adolescents: the Family Life and HIV Education (FLHE) curriculum in Nigeria and the Life Skills and HIV/AIDS Programme in South Africa.

Despite both having adopted policies and programmes in which sex education is taught, the curriculum and content of the information differs. Nigeria has a fixed curriculum which allows for uniform teaching of topics, ranging from puberty, decision making, self-esteem, communication skills, STIs, HIV and AIDS and abstinence; topics relating to contraception and pregnancy are avoided. ${ }^{24}$ South Africa allows the teaching of more in-depth topics, including sexuality, teenage pregnancy, substance abuse, HIV and STIs, contraceptive and condom use, but does not present a fixed curriculum. The lack of a fixed curriculum for teaching sexuality education in South Africa results in a lack of uniformity as the topics taught vary from school to school, resulting in different outcomes. ${ }^{25}$ In the case of Nigeria, although there is a fixed curriculum, this has not achieved much due to the fact that, despite national policy backing, the implementation of the FLHE education programme remains poor. ${ }^{26}$

South Africa makes compulsory the teaching of life skills, HIV and AIDS education from Grade R (usually at the age of six or seven), in accordance with directions from international bodies which support the introduction of sex education to children from an early age with a gradual advance in curriculum content. ${ }^{27}$ In Nigeria, although the teaching of the FLHE curriculum has been introduced in secondary schools, the teaching thereof in upper primary and private schools was only recently introduced after encouragement and financial assistance from donors. ${ }^{28}$ Despite this development, overall, sexuality education has not been successfully introduced in Nigeria.

South Africa's early introduction and 'actual' teaching of sexuality education in schools from a young age tally with what obtains

24 Durojaye (n 7 above) 2; National family life and HIV education curriculum iii \& $1-47$.

25 MJ Visser 'Life skills training as HIV/AIDS preventive strategy in secondary schools: Evaluation of a large-scale implementation process' (2005) 2 lournal of Social Aspects of HIV/AIDS 206211 214; RI Mpangana Implementation of the life skills HIV and AIDs programme in Manyeleti circuit schools unpublished LLM assignment, University of Stellenbosch, 201230

26 AO Esiet 'Adolescent sexual and reproductive health in Nigeria' (2009) http:// www.wilsoncenter.org/sites/default/files/Esiet\%20Presentation.pdf (accessed 27 July 2013).

27 WHO 'The sexual and reproductive health of younger adolescents: Research issues in developing countries' (2011) $11 \mathrm{http} / / /$ libdoc.who.int/publications/2011/9789 241501552_eng.pdf (accessed 22 August 2013).

28 RC Abah The universal basic education programme and the family life HIV education in Nigeria (2013) 2. 
internationally in countries such as Denmark, whereas Nigeria needs to adopt a realistic approach and accept the inevitability that allowing early in-depth teaching of sexuality and family life education in its schools is a positive way of disseminating and ensuring that important information on the protection of SRH generally becomes ingrained in the consciousness of adolescents.

In terms of similarities, a major resemblance in relation to the teaching of sexuality education in the two countries relates to the fact that what is accomplished by the teaching of sexuality education in schools depends on an open attitude on the part of the instructors teaching the subject. In both countries, most teachers, as a result of their religious and cultural beliefs, have reservations about teaching adolescents about sexuality. ${ }^{29}$ Also, in both Nigeria and South Africa, parents, religious leaders and other societal gate-keepers express great reluctance to discuss sexuality issues with adolescent girls, unlike the case in relation to their male counterparts.

Therefore, there is certainly a need for societal and attitudinal changes in this regard in both South Africa and Nigeria. Societal and cultural gatekeepers need to face reality, and accept the changes that have occurred in relation to adolescent sexuality. Instead of preventing access to contraceptive and other SRH care information and services, urgent steps need to be taken to ensure that adolescents are adequately informed about how to maintain good SRH.

\section{Comparing access to sexual and reproductive health care services in Nigeria and South Africa}

Both Nigeria and South Africa have adopted and implemented policies aimed at ensuring that adolescents, generally, and female adolescents, in particular, have access to contraceptive and other reproductive health care services. However, here the similarity ends. The Nigerian government has not lived up to expectations in fulfilling its obligations to ensure that female adolescents have 'actual' access to life-saving contraception and other SRH care services. ${ }^{30}$

There are too few adolescent-friendly clinics operated by the government in Nigeria. Adolescent-friendly centres administered by non-governmental organisations (NGOs) are even fewer in number in

$29 \mathrm{~N}$ Dlamini et al 'Empowering teachers to change youth practices: Evaluating teacher delivery and responses to the FLHE programme in Edo State, Nigeria' (2012) 16 African Journal of Reproductive Health 96-97; KA Smith \& K Harrison 'Teachers' attitudes towards adolescent sexuality and life skills education in rural South Africa' (2013) 13 Sex Education 69.

30 WHO The sexual and reproductive health of younger adolescents: Research issues in developing countries (2011) 11, http://libdoc.who.int/publications/2011/ 9789241501552_eng.pdf (accessed 22 August 2013); G Sedgh et al Meeting young women's sexual and reproductive health needs in Nigeria (2009) 11-16 http:// www.guttmacher.org/pubs/2009/06/03/ASRH_Nigeria.pdf (accessed 14 August 2013). 
relation to what is required to service the nation's large adolescent population. Also, as Osanyin notes, in some of the few existing clinics adolescents have to pay for contraceptives, resulting in a situation where their right to access contraception is curtailed by their economic and financial circumstances. ${ }^{31}$

By contrast, the situation in South Africa is that adolescent girls have access to contraception because there are policies that ensure the availability and accessibility of free family-planning services at public health centres. ${ }^{32}$ Additionally, collaborative efforts between the government and NGOs have resulted in the initiation of the National Adolescent-Friendly Clinic Initiative (NAFCl) programme which sets standards that are used in regulating the provision of adolescentfriendly services within the country (although not yet enough, the quantity is still greater than, presently, in Nigeria). These efforts have resulted in various adolescent clinics being operated in different parts of the country. Furthermore, the use of peer instructors increases patronage by adolescents. ${ }^{33}$

As stated earlier, the approach embraced by South Africa through the adoption of the Integrated School Health Policy, which allows adolescents access to on-site SRH services and counselling in schools, is not shared by Nigeria. Finally, from the above it is clear that there is a need for Nigeria to invest in a greater political and financial commitment towards assuring female adolescents access to contraceptive information and services, as is the case in South Africa.

\section{An overview of the barriers preventing access to sexual and reproductive health care services in Nigeria and South Africa}

Despite the differences in the extent to which their rights to access contraceptive information and services are guaranteed in the two countries, female adolescents in Nigeria and South Africa encounter

31 Y Osanyin Report on assessment of facilities providing youth-friendly health services in Nigeria (2011) 10, http://ncceonline.net/download/files/Assessment\%20of\%20 Youth\%20Friendly\%20Health\%20Centers\%20and\%20Services.pdf (accessed 3 August 2013).

32 P Maharaj \& M Rogan Reproductive health and emergency contraception in South Africa: Policy context and emerging challenges (2007) 13.

33 MIET Africa Literature review: Youth-friendly health services (2011) 14-15 http:// www.google.co.za/url?sa=t\&rct=j\&q=\&esrc=s\&frm $=1 \&$ source=web\&cd=6\&cad $=$ rja\&ved=0CEMQFjAF\&url=http\%3A\%2F\%2Fwww.miet.co.za\%2Fsite\%2Fsearch\% 2Fdownloadencode\%2FnLaaaqWMqp2zp4Sx\&ei=MQw7Uov4INKRhQfq5YGQBg \&usg=AFQjCNExpY0ySITw7Y0u3wh8hNr7EFfy-g\&bvm=bv.52288139,d.Yms (accessed 14 September 2013); AE Pettifor et al 'Challenge of evaluating a national HIV prevention programme: The case of LoveLife, South Africa' (2007) 83 Sexually Transmitted Infections 70. 
similar barriers to access, ${ }^{34}$ which not only prevent them from gaining access to essential contraceptive information and services but, ultimately, encourage their being denied the opportunity to enjoy their rights to access quality reproductive health care services, as recommended in human rights instruments and by their monitoring committees. ${ }^{35}$ Although the levels of some of the barriers experienced in the two countries may differ, a major factor remains that similar consequences result from the existence of the barriers.

As noted in the introduction, in both Nigeria and South Africa, teenage pregnancy continues to constitute a problem. In Nigeria, the adolescent birth rate is currently estimated at 123 per 1000 , one of the highest in the world. ${ }^{36}$ Despite having one of the lowest total fertility rates in the region, South Africa still has a high teenage fertility rate: Around 30 per cent of 15 to 19 year-old adolescent girls are reported as having been pregnant. ${ }^{37}$

In Nigeria and South Africa, the high rate of adolescent pregnancies is fuelled by several factors. In Nigeria it is stimulated by a lack of financial wherewithal to purchase contraceptives as free familyplanning articles are not readily available or accessible, despite government claims. Factors common to both countries include sociocultural and religious beliefs (namely, the hostile and unfriendly attitudes of health officers in charge of SRH services), general societal stigmatisation of adolescent girls who attempt to access contraception, and poverty, which encourages their engaging in transactional sex in the context of little or no bargaining power.

Another similarity occasioned as a result of inaccessibility to contraception in Nigeria and South Africa is adolescent girls' procurement of unsafe abortion services. Nigerian girls undergo these

34 The barriers which prevent female adolescents in Nigeria and South Africa from accessing contraceptive information and services range from socio-cultural, legal and religious barriers, to barriers associated with demography.

35 Art 12 ICESCR; art 25 Universal Declaration; art 12 CEDAW; arts 24(1) \& 24(2)(f) CRC; art 16 African Charter; arts 14(1), 14(2)(b) \& 14(2)(f) African Children's Charter; arts 14(1)(a), (c), (d) \& (g) African Women's Protocol; para 12 General Comment 14 of the ESCR Committee.

36 WHO The state of the world's midwifery: Delivering health, saving lives (2011) http:// www.unfpa.org/sowmy/resources/docs/country_info/profile/en_Nigeria_SoWMy_ Profile.pdf (accessed 24 June 2013); A Udo et al 'Teenage pregnancy and adverse birth outcomes in Calabar, Nigeria' (2013) 17 Internet Journal of Gynaecology and Obstetrics http://ispub.com/lJGO/17/2/2995 (accessed 10 November 2014).

37 WHO (n 36 above) 40; S Willan A review of teenage pregnancy in South Africa: Experiences of schooling, and knowledge and access to sexual and reproductive health services (2013) 7 http://www.hst.org.za/sites/default/files/Teenage\%20Pregnan cy\%20in\%20South\%20Africa\%20Final\%2010\%20May\%202013.pdf (accessed 18 September 2014); MR Ramulumo \& VJ Pitsoe 'Teenage pregnancy in South African schools: Challenges, trends and policy issues' (2013) 4 Mediterranean Journal of Social Sciences 756; Statistics South Africa General household survey (2012) 18, http://www.statssa.gov.za/publications/P0318/P0318April2012.pdf (accessed 9 November 2013). 
because obtaining safe abortion services is illegal, ${ }^{38}$ whereas South African girls procure back-street abortions because of the social stigma attached to the termination of pregnancy in the country despite the country's legalisation of abortion and the provision of free termination of pregnancy services. ${ }^{39}$

Additionally, a major similarity between the countries relates to the feminisation of HIV and other STIs among adolescent girls. This process is a major result of the continuing existence of socio-cultural beliefs and values that encourage gender imbalance, especially in relation to SRH issues. In Nigeria, the National Agency for the Control of AIDS (NACA) states that not only do females constitute 58 per cent of persons living with HIV, but the prevalence rate among young women aged 15 to 24 years is estimated to be three times higher than that among their male counterparts. ${ }^{40}$ The same situation applies in South Africa, as South African female adolescents constitute a larger percentage of adolescents infected with HIV. The prevalence rate of HIV among this group of women amounts to 11,9 per cent, compared to that of their male counterparts which stands at 5,3 per cent. ${ }^{41}$

Finally, in a majority of instances, female adolescents, Nigerian and South African, lose their chances of improving their economic and social status in life, a consequence of the denial of their right to SRH care due to the factors barring their access to contraceptive information and services. It is necessary to state here that the loss of economic empowerment occurs among South African adolescent girls despite the existence of legislation which provides that pregnant adolescents are neither to be expelled nor forbidden from returning to

38 Secs 228 \& 229 Criminal Code cap c38 LFN 2004 and secs 232 \& 233 Penal Code cap p3 LFN 2004.

39 Unsafe abortion in South Africa: A preventable pandemic (2012) http:// www.ngopulse.org/blogs/unsafe-abortion-south-africa-preventable-pandemic (accessed 9 November 2013); C Day et al 'Health and related indicators' South African Health Review (2011) 178-180, http://www.hst.org.za/sites/default/files/ Chap\% $2011 \% 20$ Indicators.pdf (accessed 11 November 2013); C MacPhail et al Contraception use and pregnancy among 15-24 year-old South African women: A nationally representative cross-sectional survey' (2013) 5 BMC Medicine http:// www.biomedcentral.com/content/pdf/1741-7015-5-31.pdf (accessed 26 June 2013).

40 NACA Key statistics on HIV in Nigeria, http://naca.gov.ng/index2.php?op tion=com_docman\&task=doc_view\&gid=110\&Itemid=268 (accessed 9 November 2013).

41 UNICEF South Africa statistics http://www.unicef.org/infobycountry/southafrica _statistics.html\#102 (accessed 28 October 2013); UNFPA HIV prevention: Fact sheet (2012) http://countryoffice.unfpa.org/filemanager/files/southafrica/HIV Preven tion_Fact_Sheet\%20.pdf (accessed 28 October 2013); C Day \& A Gray 'Health and related indicators' in A Padarath \& R English (eds) South African health review (2013) 236. 
school after giving birth, unlike the situation that normally occurs in Nigerian schools. 42

\section{Comparing the role played by the courts in ensuring access}

The approaches adopted by the national courts of Nigeria and South Africa differ in relation to intervention in matters involving the protection of the rights of children, generally, and their right to health care, in particular. South African courts have been particularly helpful in advancing the protection of the socio-economic rights of children generally (including adolescent girls). This positive contribution is bolstered by the fact that in South Africa, children's rights to basic health care and other social amenities are constitutionally guaranteed. In Nigeria, issues relating to the protection of socio-economic rights (including the right to access health care) are merely mentioned in chapter two of the country's Constitution as directive principles that are not justiciable in court. ${ }^{43}$

South African courts have been actively involved in ensuring that the rights and best interests of children are protected in several cases: the TAC case, ${ }^{44}$ in which the court declared a violation of sections 27(1) and (2) of the country's Constitution and ordered the implementation of a comprehensive programme to ensure universal access to Nevirapine, a drug used to prevent the transfer of HIV from mother to child, in public hospitals; ${ }^{45}$ the Minister of Welfare and Population Development $v$ Fitzpatrick case, $^{46}$ in which the Constitutional Court clearly declared that the 'best interests' of children principle, recognised as paramount in section 28(2) of the country's Constitution, encompassed the rights specified in section $28(1)$ to create a right on its own. ${ }^{47}$ Section $28(1)$ guarantees children's access to health care services, amongst other things.

Particularly in relation to matters concerning the protection of the SRH rights of children, and in line with decisions of the English courts in Gillick $v$ West Norfolk and Wisbech Area Health Authority \& Another ${ }^{48}$

42 Statistics South Africa (n 37 above) 18; II Ayuba \& G Owoeye 'Outcome of teenage pregnancy in the Niger Delta of Nigeria' (2012)22 Ethiopian Journal of Health Sciences 46; IN Onyeka et al 'Unintended pregnancy and termination of studies among students in Anambra state, Nigeria: Are secondary schools playing their part?' (2011) 5 African Journal of Reproductive Health 109-116; D Bhana et al 'South African teachers' responses to teenage pregnancy and teenage mothers in schools' (2012) 10 Culture, Health and Sexuality: An international journal for research, intervention and care 877.

$43 \operatorname{Sec} 6(6)(c)$ Nigerian Constitution, 1999.

44 Minister of Health $v$ Treatment Action Campaign (TAC) 2002 (5) SA 721 (CC).

45 As above.

46 Minister of Welfare and Population Development v Fitzpatrick 2000 (3) SA 422 (CC).

47 As above.

48 (1986) 1 AC 112; (1985) 3 All ER 402. 
and $R$ (Axon) $v$ Secretary of State for Health, ${ }^{49}$ that competent adolescents who understand the nature of the services requested and their implications can give consent and access confidential SRH services, South African courts in Christian Lawyers Association v Minister of Health \& Others (Reproductive Health Alliance as amicus curiae) ${ }^{50}$ refused to declare the country's Choice on Termination of Pregnancy Act of 1996 unconstitutional (this Act allows all women, including adolescents, abortion on demand up to the twelfth week of gestation). The applicants in this case argued that the Act was unconstitutional as it allowed adolescent girls, who are incapable of giving consent, access to abortion services without parental involvement. In rejecting their argument, the court explained that the Act had in place ways of ensuring that only adolescents who were mature enough to give informed consent could access abortion services in hospitals, and this preserved the rights of female adolescents in the country to confidentiality when accessing SRH care services, especially where such an adolescent staunchly refuses to inform her parents.

Also, in the recent decision of the Constitutional Court in the Teddy Bear Clinic case, ${ }^{51}$ the court, in declaring some portions of the Criminal Law (Sexual Offences and Related Matters) Amendment Act unconstitutional, noted that children enjoyed fundamental rights granted to everyone as individual bearers of human rights. According to the South African Constitutional Court, the rights to dignity of children are not only of special importance, but are also independent of the rights of their parents, and their rights are not held in abeyance until they reach a certain age.

As explained above, the right to health is not recognised as a justiciable right under the Nigerian Constitution. Nevertheless, other rights, such as the rights to life, dignity, privacy and information relevant to the right to health, are protected in the country's Constitution and can be used by the country's courts to interpret the Nigerian government's obligation to fulfil not only the rights to health care of children, but also adolescent girls' rights to access contraceptive health care services and information The Indian courts set such an example in Paschim Banga Khet Mazdoor Samity \& Others $v$ State of West Bengal \& Another. ${ }^{52}$

Additionally, taking note of the provision of the Fundamental Rights Enforcement Procedure Rules ${ }^{53}$ that mandate courts to take judicial notice of human rights instruments when determining the infringement of human rights cases, the domestic courts in Nigeria

49 (2006) EWHC 37 (Admin).

502005 (1) SA 509 (T).

51 Teddy Bear Clinic for Abused Children \& Another $v$ Minister of Justice and Constitutional Development \& Another CCT 12/13) [2013] ZACC 35; 2013 (12) BCLR 1429 (CC); 2014 (2) SA 168 (CC).

52 (1996) AIR SC 2426; (1996) 4 SCC 37.

53 Para 3(b) Preamble to Fundamental Rights (Enforcement Procedure) Rules, 2009. 
are able to act proactively, not only by taking judicial notice of international and regional human rights instruments acceded to by the country, but by extensively using the provisions of the African Charter, domesticated in Nigeria, to hold the government responsible for breaches of its obligations on the right to health, especially if such a violation is not in the best interests of children.

In this regard, the finding of a Nigerian court in Gbemre $v$ Shell Petroleum Development Company and Others, ${ }^{54}$ holding the Nigerian government accountable and liable for endangering the health of its citizens in the Niger Delta region and thereby violating their right to life as protected in section 33 of the Nigerian Constitution and their right to health in article 16 of the African Charter, is a welcome development and may serve as a precedent in children's rights cases. Similarly, the recent decision of another court in Georgina Ahamefule $v$ Imperial Medical Centre \& Alex Molokwu, ${ }^{55}$ holding the defendants liable for a violation of the provisions of article 16 of the African Charter, is encouraging.

\section{Conclusions}

As pointed out in the introduction to the article, the period of adolescence is fraught with challenges: Apart from being a stage of transition from childhood to adulthood, characterised by critical physical and psychological changes, it is also a phase in which the adolescent acquires sexual and social interaction skills that she carries with her to adulthood. As an integral function of humanity, the expression of sexuality by adolescents is natural and to be expected. However, if adolescents do not have adequate information or access to sufficient protection, this lack may have disastrous consequences. ${ }^{56}$

By virtue of the article being a report on a comparative study of female adolescents' access to contraceptive information and services in Nigeria and South Africa, we scrutinised the areas of similarity and difference in the legislation, policies and approaches adopted by the two countries, as well as barriers to access and some of the consequences of these barriers. Various issues relating to female adolescents' access to contraceptive services and information were highlighted and compared, with conclusions drawn. Also, areas of deficiency in need of reform were emphasised in order to single them out for correction.

54 (2005) Suit $\mathrm{FHC} / \mathrm{B} / \mathrm{CS} / 53 / 05$ (unreported); http://www.chr.up.ac.za/index.php/ browse-by-subject/418-nigeria-gbemre-v-shell-petroleum-development-companynigeria-limited-and-others-2005-ahrlr-151-nghc-2005.html (accessed 7 March 2013).

55 (Unreported) Suit ID/1627/2000, http://www.scribd.com/doc/126185950/Geor giana-Ahamefule-vs-Imperial-Medical-Centre-Dr-Alex-Molokwu-ID-1627-2000Judgement (accessed 8 March 2013).

56 G James 'Education and sexuality: Towards addressing adolescents' reproductive health needs in Nigeria' (2012) 4 Current Research Journal of Social Sciences 291. 
We draw the following conclusions: First, it is clear from the discussion above and, particularly, from our analysis of the legislation and its interpretation by the courts in the two countries, that, although Nigeria and South Africa are signatories to various human rights conventions and declarations guaranteeing the right to health care, including reproductive health care, based on the comparison carried out above it is evident that South Africa's legal framework on female adolescents' access to health care, including contraceptives and other SRH services, is more consistent with international provisions on the right to reproductive health than that of Nigeria.

Second, although both countries have adopted policies providing for the teaching of sexuality education to adolescents, the study shows that the content of the curriculum is predicated upon the different views and approaches adopted in the two countries. Further, adolescent girls' access to contraceptives and other SRH services in Nigeria remains elusive, as adolescent-friendly centres where the services can be obtained fail to meet the needs of the country's adolescent population.

Third, South Africa's constant review of its policies on access to contraceptive services and information and SRH generally, as evidenced by the recent National Contraception and Fertility Planning Policy and Service Delivery Guidelines and Integrated School Health Policy, reveals that there is a continuing effort to fulfil international human rights obligations. In the case of Nigeria, and in agreement with Aniekwu ${ }^{57}$ and Durojaye, ${ }^{58}$ the existence of laws and policies on $\mathrm{SRH}$ care, including access to contraceptive services for adolescent girls, has not translated into the desired result as a consequence of a lack of adequate evaluation mechanisms necessary for monitoring and co-ordinating the implementation of existing policies in order, effectively, to monitor their performance.

Fourth, and finally, despite the fact that the level and extent of the barriers faced by adolescent girls in Nigeria and South Africa when accessing contraceptive services and information vary, the consequences of the existence of these barriers are similar: We find that Nigerian and South African adolescent girls, generally, lack access to contraceptive information and services.

This leads us to the conclusion that there is an urgent need to adopt Durojaye's suggestion relating to the need for the Nigerian and South African governments to ask the 'female adolescent question'. Only if we ask the 'female adolescent question' will we be able to appraise the current state of access of adolescent girls to contraceptive information and services in the two countries, and will we be able to

57 Aniekwu (n 20 above)

58 Durojaye (n 7 above). 
put in place programmes to overcome the shortcomings evident in the legislation and policies. ${ }^{59}$

Undoubtedly, the Nigerian and South African governments have taken measures to ensure female adolescents' access to contraceptive information and services in their respective countries, but there are gaps in their strategy that require the collaboration of all interested parties if they are to be filled. Acceptance of the reality of adolescent sexual behaviour is a positive step towards the achievement of greater $\mathrm{SRH}$ results and benefits. Although the achievements realised by taking 'little' steps towards guaranteeing female adolescents' access to contraception may seem insignificant, continued advances will eventually lead to the desired result.

59 E Durojaye 'Realising access to contraception for adolescents in Nigeria: A human rights analysis' unpublished LLD thesis, University of the Free State, 201063. 